УДК $33: 338$

\title{
ПРОБЛЕМЫ КЛАССИФИКАЦИИ И ОЦЕНКИ ТРАНСАКЦИОННЫХ ИЗДЕРЖЕК НА МИКРОЭКОМИЧЕСКОМ УРОВНЕ
}

\author{
В.Э. КСЕНЗОВА
}

доцент кафедры теоретической и институциональной экономики

Белорусский государственный университет, г. Минск

\author{
C.В. КСЕНЗОВ
}

доцент кафедры международного бизнеса

Белорусский государственный экономический университет, г. Минск

\section{И.В. БАКУМЕНКО}

студент 5-го курса экономического факультета

Белорусский государственный университет, г. Минск

\begin{abstract}
Аннотация
В последнее время возрастает интерес к проблемам измерения $u$ оптимизации трансакционных издержек как на микро-, так и на макроэкономическом уровнях. Это обусловлено актуальностью такой проблемы, как повышение конкурентоспособности как продукиии отдельных фирм на внутреннем и внешнем рынках, так и в целом национальной экономики. Несомненная и объективная взаимосвязь микроu макроэкономического уровней в рамках национальной экономики позволяют сделать вывод, что оптимизация всех издержек, включая трансакиионные, на микроэкономическом (или чуть более широко мезоэкономическом) уровне является условием и фактором оптимизации ТИ макроэкономического уровня. Однако оптимизация возможно при четком и желательно однозначном представлении о сущщности оптимизируемого объекта, что в случае с трансакиионными издержками предполагает также и представление об их разновидностях, или классификации.

Ключевые слова: трансакиионные издержки, классификаичи, измерение, методика оценки.
\end{abstract}




\section{Abstract}

Lately interest increases to the problems of measuring and optimization of transakcionnykh costs both on mikro- and on macroeconomic levels. It contingently actuality of such problem, both increase of competitiveness of both products of separate firms on internal and external markets and on the whole national economy. Undoubted and objective intercommunication mikro- and macroeconomic levels within the framework of national economy allow to draw conclusion, that optimization of all costs, including transakcionnye, at mikroekonomicheskom (or hardly more widely - mezoekonomicheskom) level is a condition and factor of optimization of TI of macroeconomic level. However optimization possibly at the clear and desirably synonymous picture of essence of the optimized object, that in case with transakcionnymi costs supposes also and picture of their varieties, or classification.

Keywords: transakcionnye costs, classification, measuring, method of estimation.

\section{ВВЕДЕНИЕ}

Категория трансакционных издержек вошла в круг интересов экономистов-теоретиков не так давно - начиная с первых работ Р. Коуза, посвященных сопоставлению эффективности рынков и фирм в их возможности экономить ресурсы при осуществлении трансакций. Новый взгляд на природу фирмы как способа экономии издержек обмена между собственниками ресурсов позволил экономистам выявить, обосновать существование специфических трансакционных издержек и попытаться дать им всестороннюю характеристику. Сложность самой категории ТИ обусловлена сложностью, многогранностью и постоянной эволюцией трансакций как на уровне экономики в целом, так и на микроэкономическом уровне.

Существенный вклад в развитие теории трансакционных издержек внесли такие ученые как Р.Коуз, Дж.Коммонс, Д.Норт, Т.Эггертсон, К.Менар, О.Уильямсон, А.Алчиян, П.Милгром, Д.Робертс и др. Среди российских ученых можно выделить работы Г.Клейнера, В.Тамбовцева, А.Некипелова, В.Полтеровича, Р.Капелюшникова, А.Шаститко, В.Кокарева, Е.Попова, А.Олейника. Проблемы трансакционных издержек в контексте институциональной теории рассматриваются в работах таких белорусских ученых как П. Лемещенко, С. Солодовников, Ю. Валевич и др. 


\section{РЕЗУЛЬТАТЫ И ИХ ОБСУЖДЕНИЕ}

Существует множество определений категории ТИ. Например, К. Эрроу емко определяет их как «издержки поддержания экономических систем на ходу» [1]. Лауреат Нобелевской премии Д. Норт определяет трансакционные издержки как состоящие "из издержек оценки полезных свойств объекта обмена и издержек обеспечения прав и принуждения к их соблюдению" [2].

П. Милгром и Дж. Робертс дают более развернутое определение: «Трансакционные издержки охватывают издержки принятия решений, выработки планов и организации предстоящей деятельности, ведения переговоров о ее содержании и условиях, когда в деловые отношения вступают двое или более участников; издержки по изменению планов, пересмотру условий сделки и разрешению спорных вопросов, когда это диктуется изменившимися обстоятельствами; издержки обеспечения того, чтобы участники соблюдали достигнутые договоренности. Трансакционные издержки включают также любые потери, возникающие вследствие неэффективности совместных решений, планов, заключаемых договоров и созданных структур; неэффективных реакций на изменившиеся условия; неэффективной защиты соглашений. Одним словом, они включают все, что так или иначе отражается на сравнительной работоспособности различных способов распределения ресурсов и организации производственной деятельности» [3].

В самом общем приближении необходимо различать ТИ на микроэкономическом внутрифирменном уровне, на уровне взаимодействия отдельных субъектов экономики между собой на различных рынках, а также общеэкономические ТИ, т.е. ТИ макроэкономического уровня. На наш взгляд, наиболее существенный вклад в развитие теории внутрифирменных трансакционных издержек внес лауреат Нобелевской премии по экономике О. Уильямсон. В книге «Экономические институты капитализма» [4] им были разработаны основные методологические принципы теории:

1. Трансакция есть базовая единица анализа.

2. Любую проблему, которую прямо или косвенно можно понимать как контрактную, полезно изучать с точки зрения минимизации трансакционных издержек.

3. Экономия трансакционных издержек достигается путем дифференцированного закрепления различных трансакций за структурами управления ими (представляющими собой организационные оболочки контрактных отношений, в рамках которых обеспечивается устойчивость последних). 
4. Выбор организационной структуры происходит на основе сравнительной институциональной оценки дискретных альтернатив, среди которых классическая рыночная контрактация расположена на одном полюсе, централизованная иерархическая организация - на другом.

О. Уильямсон дает следующее определение: «трансакционные издержки - это издержки, не связанные с процессом производства. Различают exante издержки, возникающие при составлении проекта договора, ведении переговоров и обеспечении гарантий соглашения, и expost издержки, связанные с неэффективной адаптацией и корректировкой договора и возникающие, когда реализация контракта сбивается с установленного курса в результате пробелов в договоре, ошибок, упущений и непредвиденных внешних возмущений» [5].

Совершенно справедливо российский экономист А. Рысьмятов отмечает, что ТИ служат важнейшим критерием эффективности деятельности фирмы: «Трансакционные издержки - это издержки, которые «преследуют» предприятие по мере заключения им сделок. При заключении сделок фирмы, безусловно, расходуют значительные средства. Однако эти средства (трансакционные издержки) оказываются меньше, чем, если бы фирма организовывала сделку через рынок. В теории критерием оптимальности фирм является величина ее трансакционных издержек. Трансакционные издержки должны быть меньше, чем при пользовании услугами рынка. Таким образом, само существование фирмы, как таковой, подразумевает минимизацию трансакционных издержек». [6]

Этот подход к оценке важности ТИ вытекает из характеристики Р. Коузом содержания трансакционных издержек на уровне фирмы: «Для осуществления рыночной трансакции необходимо: выявить - с кем желательно заключение сделки; распространить информацию о том, что некто желает вступить в сделку и на каких условиях; провести переговоры, ведущие к заключению сделки; провести расследование, чтобы убедиться в том, что условия контракта соблюдаются, и т. п.» [7].

При оценке эффективности деятельности любой фирмы в условиях рыночной экономики следует, в том числе, определить как можно более точно ее трансакционные издержки, а также и проанализировать их динамику. Для решения этих задач необходимо выявить, какие именно ТИ характерны для данной фирмы, что в свою очередь связано с проблемами их классификации.

В научной литературе существуют различные походы к классификации ТИ. Все зависит от того критерия, который положен в основу классификации. С точки зрения масштабов объекта, по отношению к которому оцениваются ТИ, их можно разделить на две большие группы: 1) ТИ на микроэкономическом уровне, касающиеся непосредственно 
процесса рыночных трансакций отдельной фирмы; 2) ТИ на макроэкономическом уровне, рассматриваемые чаще всего как издержки общества на функционирование экономики в целом.

Если оценивать влияние ТИ на эффективность деятельности отдельных субъектов хозяйствования с точки зрения этапов заключения сделок (трансакций) в форме контрактов, то принято выделять предконтрактные ТИ, ТИ в ходе реализации проекта, и, соответственно, постконтрактные ТИ. При этом практически половина из общей суммы ТИ отдельной фирмы приходится именно на предконтрактные ТИ. Первыми классификацию на основе такого критерия предложили Д. Норт и Дж. Уоллес [8]. Они предлагали выделять соответственно следующие три группы ТИ:

- возникающие до обмена и включающие затраты на получение информации о ценах, контрагентах, качестве товара и возможных альтернативах;

- возникающие в процессе обмена - они состоят из затрат, связанных с осуществлением расчетов, ожиданием, получением документов;

- возникающие после обмена и включающие затраты по защите контрактов, проверке их выполнения и т.д.

Такой подход увязывается с наиболее распространенной классификацией внутрифирменных ТИ, подробно проанализированной в работах известного российского экономиста Р. Капелюшникова [9]. К предконтрактым ТИ можно отнести следующие:

1. Издержки поиска информации. Перед тем, как будет совершена сделка, нужно располагать информацией о том, где можно найти потенциальных покупателей или продавцов потребительских благ или производственных факторов и каковы сложившиеся на данный момент цены. Издержки такого рода складываются из затрат времени и ресурсов, необходимых для ведения поиска, а также из потерь, связанных с неполнотой и несовершенством получаемой информации.

2. Издержки ведения переговоров. Рынок требует отвлечения значительных средств на проведение переговоров об условиях обмена, на заключение и оформление контрактов. Чем больше участников сделки и чем сложнее ее предмет, тем выше эти издержки. Дополнительным их источником являются потери из-за неудачно заключенных, плохо оформленных и ненадежно защищенных соглашений.

3. Издержки измерения. Любой продукт или услуга это комплекс характеристик. В акте обмена неизбежно учитываются лишь некоторые из них, причем точность их оценки (измерения) бывает чрезвычайно приблизительной. Измерение это квантификация информации. Фактически ни один товар, выносимый на продажу, не свободен 
от издержек измерения его свойств. Важным способом минимизации издержек измерения является также вертикальная интеграция (организация фирмы).

В ходе реализации контракта, a также постконтрактного обслуживания возникают следующие виды ТИ:

1. Издержки спецификации и защиты прав собственности. В эту категорию входят расходы на содержание судов, арбитража, государственных органов, затраты времени и ресурсов, необходимых для восстановления нарушенных прав, а также потери от плохой их спецификации и ненадежной защиты. Любое нарушение требуется сначала зафиксировать, затем оценить его тяжесть, обеспечить поимку или явку нарушителя, наложить наказание. Все это далеко не бесплатно. Некоторые авторы (Д. Норт) относят сюда же затраты на поддержание в обществе консенсусной идеологии, поскольку воспитание членов общества в духе соблюдения общепринятых неписаных правил и этических норм является во многих случаях более экономным способом защиты прав собственности, чем формализованный юридический контроль.

2. Издержки оппортунистического поведения. Термин «оппортунистическое поведение» был введен О. Уильямсоном. Так называется недобросовестное поведение, нарушающее условия сделки или нацеленное на получение односторонних выгод в ущерб партнеру. В эту категорию попадают различные случаи лжи, обмана, бездельничанья на работе, манкирования взятыми на себя обязательствами и т.д.

3. Издержки «политизации». Этим общим термином можно обозначить издержки, сопровождающие принятие решений внутри организаций. Принятие решений на рынке и в организации носит различный характер. Рыночная сделка будет заключена только в том случае, если от нее выигрывают обе стороны. Всякий, кто считает, что сделка ему невыгодна, имеет возможность от нее отказаться. Добровольное обоюдное согласие дает минимальную гарантию эффективности принимаемых на рынке решений, поскольку их необходимым условием является ожидаемое повышение благосостояния обоих участников (или, по меньшей мере, не ухудшение благосостояния хотя бы одного из них).

В. Ильяшенко предлагает рассматривать еще один важный вид внутрифирменных ТИ - издержки анализа эффективности трансакции: «Издержки анализа эффективности трансакции характеризуют процесс анализа эффективности по той или иной трансакции, в результате которой происходит снижение (увеличение) её стоимости по взаимному согласию сторон или в одностороннем порядке (без ущемления прав другой стороны)... Поскольку контракт является документом, который выражает 
взаимные интересы сторон, то в результате анализа его эффективности могут обозначиться скрытые издержки, которые возникают только при детальном расчете с учетом всех внешних и внутренних особенностей, аспектов по условиям контракта... Причем речь идет не о глобальных издержках, попадающих в разряд форс-мажорных обстоятельств, которые прописаны в соответствующих статьях контракта, а об обстоятельствах, которые стороны по контракту определяют самостоятельно, за свой счет, признавая свои недоработки или оказываясь в безвыходном положении перед наступлением каких-либо возникших обстоятельств, увеличивающих стоимость их контракта, т.е. несущих в себе трансакционные издержки». [10]

О.В. Шумакова предлагает классификацию внутрифирменных ТИ в зависимости от степени влияния фирмы на продвижение своего товара на рынке:

- внутрипроизводственные, которые представляют собой затраты, непосредственно связанные с продвижением товаров на рынке собственными подразделениями хозяйствующего субъекта;

- внешние, которые включают затраты, обусловленные покупкой услуг сторонних организаций, способствующих продвижению товаров на рынке;

- в форме недополученной выручки: затраты (издержки) возникают, когда происходят потери ... части выручки в результате расхождений качественных показателей продаваемого товара, реализации продукции в сроки и по ценам в ущерб собственной выгоде, а также потери физического объёма продукции в процессе реализации. [11]

C точки зрения совокупности процессов, происходящих на предприятии в ходе реализации проектов (как на кратко-, так и на долгосрочной основе) ТИ можно классифицировать следующим образом: «1) административные трансакционные издержки, возникающие на уровне административного управления, или трансакционные издержки, возникающие при выполнении обязательных нормативных требований. Это издержки доступа к ресурсам и правам собственности, оппортунистического поведения, спецификации и защиты прав собственности; 2) трансакционные издержки, возникающие в процессе осуществления предприятием хозяйственной деятельности. В свою очередь данный блок трансакционных издержек классифицируется по признаку направления хозяйственной деятельности предприятия, а именно: 2.1) трансакционные издержки, возникающие при осуществлении хозяйственной деятельности предприятия на внутреннем рынке. Данные трансакционные издержки сопровождают как внутриэкономические операции предприятий, так и внешнеторговые сделки. Такие 
трансакционные издержки представляют собой издержки обращения, возникающие при закупке средств производства, материалов, комплектующих; 2.2) трансакционные издержки экспортно-импортной деятельности предприятия, возникающие на предконтрактной, контрактной и постконтрактной стадиях внешнеэкономической сделки» [12].

В качестве базовых признаков классификации трансакционных издержек отдельной фирмы, по мнению Л.О. Оганесяна и И.А. Гущиной, «могут служить внутренние и внешние условия функционирования рынка. Если к внутренним трансакционным издержкам фирмы относятся издержки, возникающие в процессе организации хозяйственной деятельности внутри предприятия, трансформации, то внешние это издержки, возникающие в результате взаимодействия фирмы с другими контрагентами (издержки информации, адаптации, координации и оппортунистического поведения). По способу учета фирмой соответствующих затрат трансакционные издержки подразделяются на издержки, включаемые в себестоимость продукции; выплачиваемые из прибыли, остающейся в распоряжении фирмы; включаемые в состав внереализационных расходов; не учитываемые в структуре издержек. По способу измерения трансакционные издержки делят на издержки, имеющие и не имеющие количественное выражение. К первой группе относятся трансакционные издержки, которые фирма непосредственно оплачивает внешним контрагентам. Это прежде всего издержки поиска и приобретения информации (информационно-справочное, консультационное обслуживание, маркетинговые исследования), издержки приобретения и закрепления прав собственности (регистрация, лицензирование, заключение контрактов) и издержки защиты прав собственности (юридические услуги, судебные издержки). Ко второй группе относятся трансакционные издержки, которые фирма не оплачивает внешним контрагентам и которые могут быть выражены опосредованно в виде убытков, потерь, упущенных выгод, штрафов, пеней. В эту группу входят издержки оппортунистического поведения, использования неполной и недостоверной информации, ухудшения отношений клиентов к фирме, падения спроса на продукцию фирмы, недоброжелательной обстановки в коллективе» [13].

Данные экономисты предлагают выделять следующие разновидности ТИ отдельной фирмы [14]:

Издержки информации:

- издержки, связанные с выходом на рынок;

- издержки спецификации и защиты прав собственности;

- издержки поиска и отбора партнеров; 
- издержки, связанные с заключением контракта.

Издержки взаимодействия:

- издержки определения деталей контракта;

- издержки определения контрактов;

- издержки непосредственной координации и взаимодействия;

- политические трансакционные издержки;

- издержки реализации контрактов.

Издержки мотивации:

- издержки, связанные с неполнотой информации;

- издержки оппортунистического поведения;

- издержки ограниченности и асимметричности информации.

Издержки адаптации:

- издержки приспособления к изменениям (институциональным, экономическим и структурным), изменениям под воздействием внутренних и внешних факторов.

Интересна классификация ТИ с точки зрения возможности их количественного измерения, предложенная Л.В. Поповой и Е.В. Вобленко. К ТИ, подлежащим количественной оценке, можно отнести ТИ, «которые предприятие оплачивает внешним контрагентам: издержки поиска и приобретения информации (информационно-справочное, консультационное обслуживание, маркетинговые исследования); издержки приобретения и закрепления прав собственности (регистрация, лицензирование, заключение контрактов); издержки защиты прав собственности (юридические услуги, судебные издержки). Ко второй группе относятся: издержки оппортунистического поведения; издержки использования неполной и недостоверной информации; падение спроса на продукцию предприятия; неблагоприятный микроклимат в коллективе и т.п.» [15]

На основе анализа жизненного цикла фирмы, проведенного Адизесом И. [16], Подопригора М.Г. [17] предложил оригинальную классификацию внутрифирменных ТИ, которая позволяет в максимальной степени учитывать последние в зависимости от стадии существования и функционирования фирмы. Внутрифирменные ТИ анализируюся по следующим стадиям: ухаживание, младенчество, «давай-давай», юность, ранний расцвет, поздний расцвет, закат, аристократизм, СалемСити, бюрократизм, смерть.

Мы полагаем, что для определения внутрифирменных трансакционных издержек можно использовать их условное деление на постоянные и одноразовые. Часть из них (как предконтрактные, так и постконтрактные) фирма несет на протяжении всего времени своего функционирования. Например, поиск и обработка информации о клиентах 
и поставщиках фирмы, о рыночной конъюнктуре, об изменениях спроса на продукт фирмы и на товары-субституты и т.п. Требуется содержание маркетинговых и сбытовых отделов фирмы, что является постоянными трансакционными издержками. Однако «постоянность» таких издержек отличается от постоянных трансформационных издержек фирмы в краткосрочном периоде. Постоянные ТИ могут зависеть от различных факторов, в том числе и от объема производимой продукции. К одноразовым трансакционным издержкам относятся те, которые возникают только в связи с определенной разовой сделкой. Например, при получении лицензии на совершение конкретной операции.

Таким образом, существует множество классификаций внутрифирменных трансакционных издержек. Однако все они так или иначе выделяют издержки, связанные с заключением контрактов и с их исполнением. При этом возникает сложная методологическая и методическая проблема измерения, количественной оценки ТИ.

Измерение трансакционных издержек фирмы является весьма важным и актуальным для любой фирмы в любой отрасли деятельности, поскольку сбор, количественная оценка, обобщение и анализ всего комплекса информации о ТИ позволит руководству фирмы принимать оптимальные управленческие решения. По справедливому замечанию О. Тисенковой, «в настоящее время методика количественной оценки трансакционных издержек не отработана. Это обусловлено и трудностью измерения некоторых видов трансакционных издержек, их “неосязаемостью”, и многообразием подходов к их определению. Невозможность исчисления всех трансакционных издержек также связана со следующим: часть трансакционных издержек не подвержена прямому измерению; многие издержки связаны с неформальным обменом услугами; трансакционные издержки часто невозможно отделить от "производственных" издержек; трансакционные издержки включают разнородные элементы, и их суммирование порождает дополнительные проблемы» [18].

Проблема измеримости трансакционных издержек остается одним из главных препятствий в конкретном экономическом анализе. В этой связи Н.Ш. Шакиров отмечает: «Во-первых, остается открытым вопрос, могут ли все типы трансакционных издержек быть измеренными в денежном эквиваленте (ДТИ - денежные трансакционные издержки). Во-вторых, возникают вопросы при попытках оценить в денежной форме те издержки, которые не принимают эксплицитной формы, например, психологический дискомфорт, возникающий по причине оппортунистического поведения партнера, пользовавшегося ранее доверием, или в связи с незащищенностью прав собственности» [19]. 
Приходится констатировать, что в настоящее время не выработана методика прямого расчета ТИ, которая бы была приемлемой для предприятий любого масштаба и любой сферы деятельности. А при отсутствии универсальных прямых методов расчета трансакционных издержек актуальным становится вопрос разработки метода косвенной оценки трансакционных издержек предприятия, позволяющей не только оценить эти издержки, но и измерить их. И.С. Вологин и В.В. Соколенко предлагают свою методику косвенной оценки ТИ для промышленных предприятий: «Косвенный метод учета трансакционных издержек промышленного предприятия должен основываться на выборке предприятий определенного сектора промышленности. Полученные статистические и анкетные данные с выбранных предприятий обрабатываются, и рассчитывается размер соответствующих трансакционных издержек в зависимости от объемов производства предприятия. При этом методика должна быть направлена на изучение как внешних, так и внутренних трансакционных издержек предприятия промышленности, ведь зачастую внутренние издержки намного превышают внешние из-за отсутствия налаженного механизма организации процессов внутри предприятия и наличия внутренних издержек оппортунизма» [20].

Данный косвенный метод оценки трансакционных издержек должен отвечать следующим требованиям:

- быть универсальным для всех предприятий выбранного направления;

- учитывать все виды трансакционных издержек;

- предоставлять возможность оценки по данным бухгалтерской отчетности.

Авторы такого подхода учета ТИ промышленного предприятия предлагают все ТИ четко распределить при учете на определенные группы в зависимости от той или иной классификации последних:

Таблица 1 - Схема определения метода учета и источников информации о трансакционных издержках промышленных предприятий

\begin{tabular}{|c|c|c|l|}
\hline $\begin{array}{c}\text { № } \\
\text { п/п }\end{array}$ & $\begin{array}{c}\text { Классификация } \\
\text { трансакционых издержек }\end{array}$ & Метод учета & \multicolumn{1}{|c|}{ Источник информации } \\
\hline $\mathbf{1}$ & $\mathbf{2}$ & $\mathbf{3}$ & $\mathbf{4}$ \\
\hline \multirow{2}{*}{1} & Издержки поиска информации & Прямой & $\begin{array}{l}\text { Бухгалтерская документация, } \\
\text { счета-фактуры, накладные }\end{array}$ \\
\cline { 2 - 4 } & Издержки ведения переговоров & Прямой & $\begin{array}{l}\text { Бухгалтерская документация, } \\
\text { счета-фактуры, накладные }\end{array}$ \\
\hline
\end{tabular}


Окончание таблицы 1

\begin{tabular}{|c|c|c|c|}
\hline 1 & 2 & 3 & 4 \\
\hline \multirow{3}{*}{1} & Издержки измерения & Прямой & $\begin{array}{l}\text { Бухгалтерская документация, } \\
\text { счета-фактуры, накладные }\end{array}$ \\
\hline & $\begin{array}{l}\text { Издержки спецификации и } \\
\text { защиты прав собственности }\end{array}$ & $\begin{array}{l}\text { Прямой и } \\
\text { косвенный }\end{array}$ & $\begin{array}{l}\text { Бухгалтерская документация, } \\
\text { счета-фактуры, накладные, } \\
\text { статистические данные }\end{array}$ \\
\hline & $\begin{array}{l}\text { Издержки оппортунистического } \\
\text { поведения }\end{array}$ & Косвенный & $\begin{array}{l}\text { Анкетирование, статистические } \\
\text { данные }\end{array}$ \\
\hline \multirow{2}{*}{2} & Явные (эксплицитные) & Прямой & $\begin{array}{l}\text { Бухгалтерская документация, } \\
\text { счета-фактуры, накладные }\end{array}$ \\
\hline & Неявные (имплицитные) & Косвенный & $\begin{array}{l}\text { Анкетирование, статистические } \\
\text { данные }\end{array}$ \\
\hline \multirow{2}{*}{3} & Измеримые & Прямой & $\begin{array}{l}\text { Бухгалтерская документация, } \\
\text { счета-фактуры, накладные }\end{array}$ \\
\hline & Не измеримые & & $\begin{array}{l}\text { Анкетирование, статистические } \\
\text { данные }\end{array}$ \\
\hline \multirow{2}{*}{4} & $\begin{array}{l}\text { Отраженные в бухгалтерском } \\
\text { учете (статистике) }\end{array}$ & Прямой & $\begin{array}{l}\text { Бухгалтерская документация, } \\
\text { счета-фактуры, накладные }\end{array}$ \\
\hline & $\begin{array}{l}\text { Не отраженные в бухгалтерском } \\
\text { учете (статистике) }\end{array}$ & Косвенный & $\begin{array}{l}\text { Анкетирование, статистические } \\
\text { данные }\end{array}$ \\
\hline \multirow[b]{2}{*}{5} & Внутренние & Прямой & $\begin{array}{l}\text { Бухгалтерская документация, } \\
\text { счета-фактуры, накладные }\end{array}$ \\
\hline & Внешние & $\begin{array}{l}\text { Прямой и } \\
\text { косвенный }\end{array}$ & $\begin{array}{l}\text { Бухгалтерская документация, } \\
\text { счета-фактуры, накладные, } \\
\text { статистические данные, } \\
\text { анкетирование }\end{array}$ \\
\hline
\end{tabular}

Источник: [20]

В качестве прямого метода оценки трансакционных издержек отдельных трансакций предлагается так называемый расчет издержек процесса. Оценка трансакций по этому методу предпочтительна в тех случаях, когда оцениваемые процессы часто повторяются, а диапазон принимаемых решений относительно узок (например, проверка принимаемой продукции или обработка рекламаций).

Томас М. Фишер в работе «Координация управлением качеством в свете теории трансакционных издержек» [21] показывает границы применения такого метода оценки ТИ. Чтобы идентифицировать поля применения метода количественного исчисления издержек процесса для той или иной трансакции, целесообразно рассмотреть характер альтернативных вариантов в разрезе трех теоретически возможных видов обменных отношений.

Устойчивые хозяйственные связи или единичная акция. При обменных процессах, протекающих в рамках хозяйственных связей, предприятие-поставщик хорошо знает своего клиента. По опыту прошлых сделок оно располагает специфическим "ноу-хау" в общении со "старым клиентом", что позволяет со временем стандартизировать регулярно повторяющиеся процессы. Возможность применения метода расчета 
издержек процесса для количественного определения трансакционных издержек повышается по мере того, как увеличивается продолжительность хозяйственных отношений и растет частота выдаваемых заказов.

Повторная или первая сделка. Подобная альтернатива означает, что предметом трансакции является "старая" или "новая" услуга. Повторное приобретение "старой" услуги приводит к формированию однородных, стандартизованных трансакционных процессов, которые в этом случае ориентируется не на клиента, а на специфическую услугу. В случае "новой" услуги предприятие-поставщик располагает явно меньшим "ноу-хау" в отношении соответствующего трансакционного процесса.

Обменный или контрактный товар. Неопределенность относительно трансакции для контрактных товаров проявляется значительно сильнее, чем при обменных операциях. Контрактные товары содержат, как правило, большую долю неповторяющихся компонентов, тогда как определенные обменные процессы (например, фактурирование) повторяются с высокой степенью сходства. Стандартизация процессов в отношении обменных товаров вполне возможна. Следовательно, соответствующие трансакционные издержки лучше поддаются количественному определению, чем при трансакциях с контрактными товарами.

Сложность точного измерения ТИ связана с тем, что нет типовых и общепринятых методик их учета и измерения. Приходится использовать самые разнообразные источники информации, главным образом, бухгалтерскую отчетность. Кроме того, некоторые виды ТИ можно определить только косвенно. Это связано не только с отсутствием методик расчета, но и со сложностью выявления самих издержек.

Стукач В.Ф. и Крюкова О.Н. предложили рассчитывать следующие виды внутрифирменных издержек (таблица 2).

\section{Таблица 2 - Внутрифирменные трансакционные издержки}

\begin{tabular}{|l|l|}
\hline Издержки поиска информации & $\begin{array}{l}\text { Затраты на покупку информации о рынке, затраты на } \\
\text { аудиторскую проверку фирмы }\end{array}$ \\
\hline $\begin{array}{l}\text { Издержки ведения } \\
\text { переговоров }\end{array}$ & $\begin{array}{l}\text { Затраты оплаты труда менеджеров, представительские } \\
\text { расходы }\end{array}$ \\
\hline Издержки измерения & Затраты на составление сертификата качества товаров \\
\hline $\begin{array}{l}\text { Издержки заключения } \\
\text { контракта }\end{array}$ & $\begin{array}{l}\text { Оплата труда юристов, секретарей, связанного с оформлением } \\
\text { сделок }\end{array}$ \\
\hline $\begin{array}{l}\text { пздержки мониторинга и } \\
\text { оппортунизма }\end{array}$ & $\begin{array}{l}\text { Размеры штрафов, пени и т.п., а также процент, } \\
\text { предусмотренные в договорах за невыполнение условий } \\
\text { контракта }\end{array}$ \\
\hline $\begin{array}{l}\text { Издержки спецификации и } \\
\text { защиты прав собственности }\end{array}$ & $\begin{array}{l}\text { Затраты на содержание вневедомственных охранных } \\
\text { предприятий, а также налоги, связанные с содержанием } \\
\text { правоохранительных органов, заработная плата юристов, } \\
\text { консультации по юридическим вопросам }\end{array}$ \\
\hline
\end{tabular}


Окончание таблицы 2

\begin{tabular}{|l|l|}
\hline $\begin{array}{l}\text { Издержки защиты от третьих } \\
\text { лиц }\end{array}$ & Налоги, связанные с содержанием налоговых органов, «откат» \\
\hline Аудит & Оплата аудиторов \\
\hline
\end{tabular}

Источник: [22].

Поскольку данные виды ТИ существуют практически на любом предприятии, то такой подход в группировке ТИ для расчета вполне приемлем. При этом необходимо учитывать специфику той внешней и внутренней среды, в которой действует конкретное предприятие. Поэтому могут добавляться в предложенную систему новые виды ТИ, производиться их более детальное деление и т.д. Однако, как правило, из имеющейся отчетности относительно точно можно измерить укрупнено такие виды внутрифирменных ТИ как:

- расходы на управленческий персонал, так как они отражают денежные затраты на организацию производства и согласование внутрикорпоративных бизнес-процессов;

- расходы на реализацию продукции, что непосредственно влияет на результаты деятельности предприятия. Сюда относятся все расходы на маркетинговые мероприятия, рекламу, организацию взаимоотношений с торговыми предприятиями.

В качестве примера можно привести данные по репрезентативному предприятию в сфере пищевой промышленности Республики Беларусь, таблица 3.

Таблица 3 - Управленческие расходы и расходы на реализацию продукции в структуре себестоимости реализованных товаров

\begin{tabular}{|l|c|c|c|c|c|}
\hline Годы & $\begin{array}{c}\text { Себестоимость } \\
\text { реализованных } \\
\text { товаров, } \\
\text { млн руб. }\end{array}$ & $\begin{array}{c}\text { Управленческие } \\
\text { расходы, } \\
\text { млн руб. }\end{array}$ & $\begin{array}{c}\text { Доля в } \\
\text { себестоимости } \\
\text { реализованных } \\
\text { товаров, \% }\end{array}$ & $\begin{array}{c}\text { Расходы на } \\
\text { реализацию } \\
\text { продукции, } \\
\text { млн руб. }\end{array}$ & $\begin{array}{c}\text { Доля в } \\
\text { себестоимости } \\
\text { реализованных } \\
\text { товаров, \% }\end{array}$ \\
\hline $\mathbf{2 0 1 1}$ г. & 364438 & 5300 & 1,45 & 5968 & 1,63 \\
\hline $\mathbf{2 0 1 2}$ г. & 697356 & 9512 & 1,36 & 17820 & 2,55 \\
\hline $\mathbf{2 0 1 3}$ г. & 821638 & 12457 & 1,52 & 23158 & 2,82 \\
\hline
\end{tabular}

Таким образом, суммарно доля управленческих расходов и расходов на реализацию продукции в себестоимости реализованных товаров составила: в 2011 г. - 3,08\%, в 2012 г. - 3,91\%, в 2013 г. - 4,34\%. Это достаточно значительные величины, размер и динамика которых существенно влияют на себестоимость продукции, а, следовательно, и на ее конкурентоспособность.

Также достаточно явными являются многие виды ТИ, связанные с оппортунистическим поведением как внутри фирмы (ее собственных работников), так и внешних контрагентов, таких как поставщики сырья 
и потребители продукции данной фирмы. В частности, существующая бухгалтерская отчетность предполагает учет таких видов данных ТИ, как недостачи, хищения и порча товарно-материальных и других ценностей; недостачи, хищения и порча сырья, полуфабрикатов и готовой произведенной продукции; расходы по охране имущества.

На наш взгляд, проблема оппортунистического поведения в определенной степени решается путем проведения соответствующей воспитательной работы на предприятии, а также через организацию мероприятий, формирующих у работников положительное отношение и к руководству фирмы, и к самой фирме, вызывающих желание эффективно трудиться, соблюдать правила внутреннего распорядка. Для этого работник должен чувствовать внимание и заботу по отношению к себе со стороны руководства. Поэтому мы считаем, что к данной категории ТИ можно отнести следующие: социальные расходы предприятия, расходы на услуги образования и здравоохранения, расходы по жилищнокоммунальному хозяйству и социальному развитию, отнесенные к трансакционным.

ТИ являются составной и достаточно существенной частью общих издержек фирмы. Их нельзя игнорировать, так как они влияют как на общие расходы фирмы, так и на эффективность ее деятельности. При этом статистика не выделяет их в отдельную группу, что порождает проблему их измерения. Сложность измерения заключается так же в том, что значительная доля в структуре общих внутрифирменных ТИ приходится на потери времени, связанные и с поиском клиентов, и с оформлением различных документов, и с оппортунистическим поведением (отлыниванием) работников фирмы и т.п. Также необходимо учитывать, что часть расходов фирмы не может быть однозначно отнесена либо к трансформационным, либо к трансакционным издержкам. Например, расходы по упаковке готовой продукции и ее маркировке, транспортные издержки, особенно когда речь идет о транспортировке между подразделениями фирмы, расходы по оплате труда менеджеров и т.д.

Еще одна из причин сложности в измерении трансакционных издержек, на наш взгляд, заключается в том, что они оказывают различное влияние на эффективность функционирования фирмы. С одной стороны, невозможно включаться в рыночные процессы, не неся расходов на изучение рыночной конъюнктуры, на рекламу своей продукции, на заключение контрактов с внешними контрагентами. Например, для предприятий, связанных с производством продуктов потребительского назначения, совершенно необходимыми являются издержки измерения, в частности, расходы на содержание лабораторий, проведение санитарноэпидемиологических мероприятий и т.п. С другой стороны, излишние 
административные расходы, содержание многочисленных подразделений обслуживания основного производственного процесса, часто дублирующих работу друг друга и т.п. могут существенно снижать общую эффективность и рентабельность производственной деятельности фирмы, что ухудшит ее положение на рынке, снизив конкурентные преимущества. При этом в административных расходах довольно сложно выявить те, которые объективно обусловлены задачами оптимизации управленческих процессов, и те, которые ведут к снижению эффективности функционирования фирмы. Все это не способствует заинтересованности управленцев (менеджеров) в выделении, измерении и анализе внутрифирменных ТИ с целью их дальнейшей оптимизации.

Сама отчетность на предприятии не позволяет ни четко сгруппировать ТИ по категориям, ни однозначно их измерить. Это связано со слабой теоретико-методологической обоснованностью важности измерения внутрифирменных ТИ, с отсутствием методик их расчета, с различными подходами к их классификации и группировке. При этом фирма, стремящаяся занимать в долгосрочной перспективе свою нишу на рынке, сохранять и укреплять свои конкурентные преимущества, обеспечивать положительную (или как минимум постоянную) динамику прибыльности и рентабельности, объективно заинтересована в анализе внутрифирменных ТИ, часть из которых напрямую влияет на ее «выживаемость» в условиях конкурентной борьбы.

Часть расходов, которые мы можем отнести к внутрифирменным ТИ, отражается в статистической отчетности предприятия и поддается точному учету. Часть можно определить косвенно через другие показатели, не имеющие однозначной идентификации как трансакционные издержки. Есть и такие виды ТИ, которые не подлежат более-менее точному подсчету в силу их специфики.

Мы полагаем, что можно структурировать ТИ предприятия, исходя из возможности их определения. К первой группе можно отнести те ТИ, которые поддаются точному измерению, так как отражаются однозначно в официальной отчетности. Например, для выбранного репрезентативного предприятия можно выделить следующие виды в данной группе ТИ, таблица 4.

Таблица 4 - Трансакционные издержки предприятия, подлежащие точному учету, млн руб.

\begin{tabular}{|l|c|c|c|}
\hline \multicolumn{1}{|c|}{ Виды издержек } & $\mathbf{2 0 1 1}$ год & $\mathbf{2 0 1 2}$ год & $\mathbf{2 0 1 3}$ год \\
\hline 1. Издержки на поиск информации: & & & \\
\hline $\begin{array}{l}\text { расходы на консультационные и аудиторские } \\
\text { услуги }\end{array}$ & 69 & 127 & 186 \\
\hline
\end{tabular}


Окончание таблицы 4

\begin{tabular}{|l|c|c|c|}
\hline \multicolumn{1}{|c|}{ Виды издержек } & $\mathbf{2 0 1 1}$ год & $\mathbf{2 0 1 2}$ год & $\mathbf{2 0 1 3}$ год \\
\hline $\begin{array}{l}\text { 2. Издержки ведения переговоров и заключения } \\
\text { контрактов }\end{array}$ & & & \\
\hline Оплата труда менеджеров (усредненно) & 366 & 366 & 366 \\
\hline Командировочные расходы & 279 & 220 & 256 \\
\hline Расходы на рекламу & 388 & 519 & 624 \\
\hline 3. Издержки оппортунистического поведения & & & \\
\hline $\begin{array}{l}\text { Потери от порчи и повреждения товарно- } \\
\text { материальных ценностей, списанных на виновных } \\
\text { лиц }\end{array}$ & 9 & 34 & 26 \\
\hline Расходы по охране имущества & 656 & 1305 & 1395 \\
\hline Социальные расходы & 18239 & 25600 & 23418 \\
\hline Расходы на услуги образования и здравоохранения & 85 & 109 & 137 \\
\hline $\begin{array}{l}\text { Расходы по жилищно-коммунальному хозяйству и } \\
\text { социальному развитию }\end{array}$ & 539 & 722 & 1185 \\
\hline Итого: & 20630 & 29002 & 27593 \\
\hline
\end{tabular}

Источник: данные годовых отчетов репрезентативного предприятия за $2011-2013$ гг.

Сюда же можно включать и разовые ТИ, например, такие как:

1) Расходы на имущественные права на программы для ЭВМ и компьютерные базы данных. Они были осуществлены один раз в 2011 году и составили 24 млн.руб.

2) Затраты на сертификацию и декларирование продукции в размере 300 млн. руб., которые были осуществлены в 2014 году.

Можно также анализировать те ТИ, которые представлены в расходах по реализации продукции. В отчетности предприятия они называются коммерческими расходами (счет 43) и включают в себя около 100 позиций, среди которых, в частности, выделяются следующие виды расходов, которые мы однозначно отнесем с трансакционным:

Таблица 5 - Трансакционные издержки предприятия в составе коммерческих расходов, руб.

\begin{tabular}{|l|r|r|}
\hline \multicolumn{1}{|c|}{ Виды издержек } & \multicolumn{1}{c|}{$\mathbf{2 0 1 4}$ г. } & \multicolumn{1}{c|}{$\mathbf{2 0 1 5}$ г. } \\
\hline Нанесение печати на упаковку & & \\
\hline Расходы на страхование & 14410000 & \\
\hline Реклама в интернете & 263619950 & 373836810 \\
\hline Внутренняя реклама & & 96419185 \\
\hline Наружная реклама & & 52791378 \\
\hline Реклама в печатных СМИ и на телевидении & 255160000 & 190786560 \\
\hline
\end{tabular}


Окончание таблицы 5

\begin{tabular}{|l|r|r|}
\hline \multicolumn{1}{|c|}{ Виды издержек } & 2014 г. & \multicolumn{1}{|c|}{$\mathbf{2 0 1 5}$ г. } \\
\hline $\begin{array}{l}\text { Расходы на выставки и дегустацию } \\
\text { продукции }\end{array}$ & 495222000 & 852898000 \\
\hline Расходы на участие в конкурсах & 7738000 & 15243000 \\
\hline Маркетинговые исследования & 16131372 & 103482530 \\
\hline
\end{tabular}

Источник: данные годовых отчетов репрезентативного предприятия за $2011-2013$ гг.

Также в структуре коммерческих расходов выделяются и точно подсчитываются расходы на лабораторные исследования и оплату услуг ветеринарных служб, которые относятся в данном случае к издержкам измерения.

Ко второй группе можно отнести расходы на заработную плату специалистов, которые заняты преимущественно в работе тех отделов, затраты на содержание которых мы можем отнести к различным категориям внутрифирменных трансакционных издержек. На изучаемом предприятии к числу таких отделов можно отнести следующие: юридическое бюро (2 специалиста); отдел кадров и подготовки кадров (3 специалиста); бухгалтерия (17 специалистов); отдел по ВЭД (5 специалистов); отдел торговли (8 специалистов). Заработная плата этих работников (35 человек) может быть однозначно отнесена к трансакционным издержкам предприятия. На наш взгляд, в целом представление об этой группе ТИ дает информация счета 26 «Общехозяйственные расходы» по управленческим расходам. Однако в целом очень сложно выделить статьи в счете 26 «Общехозяйственные расходы», которые однозначно характеризовали бы именно ТИ.

Еще более сложно определить расходы на материальные ресурсы, требуемые для содержания соответствующих помещений и т.П., так как они не выделяются в отдельные группы в статистической отчетности предприятия. Но при условии доступности информации можно выделить расходы на амортизацию конкретных основных фондов, расходы на приобретение товарно-материальных ценностей для соответствующих служб и помещений.

Некоторые авторы предлагают рассчитывать такой вид вутрифирменных ТИ как административные: «Методический подход к оценке административных трансакционных издержек учитывает, что они включают в себя регулярные трансакционные издержки предприятия, возникающие при выполнении обязательных нормативных требований в своей текущей хозяйственной деятельности и единовременные трансакционные издержки на преодоление административных барьеров, которые имеют место в течение года с определенной степенью 
вероятности». [23]. Автор даже предлагает формулы для расчета таких ТИ: 1) $\mathrm{P} 3=3 \mathrm{BP}+3 \mathrm{HУ}$ (где $\mathrm{P} 3-$ регулярные административные трансакционные издержки; ЗВР - затраты в связи с потерей времени руководства на выполнение общих нормативных требований; ЗНУ затраты времени на налоговый учет); 2) Е3 = Зпров + Злиц + Зрег (где Е3 единовременные административные трансакционные издержки; Зпров затраты в связи с проверками; Злиц - затраты на лицензирование; Зрег затраты времени на регистрацию предприятия). Совершенно очевидно, что такой вид ТИ нельзя определить на основе бухгалтерской отчетности и данных годовых отчетов. Это аналитическая работа, которая проводится исключительно с целью выявления влияния такого рода ТИ на общую конкурентоспособность фирмы на рынке. Ведь основной параметр для измерения - это потери рабочего времени на совершение тех или иных административных действий. При этом не всегда очевидны эти потери, так как они «маскируются» в общем рабочем времени, особенно при использовании повременной системы оплаты труда. И уж совершенно не учитывается статистикой то время, которое потрачено служащим «за пределами» рабочего дня или недели. А такие потери существуют и могут отвлекать значительные человеческие ресурсы. Их надо анализировать в целях оптимизации использования такого редкого ресурса как время. При этом фактически возникает новый вид внутрифирменных ТИ расходы на проведение самой этой аналитической работы. Однако такую работу может проводить экономист из числа уже занятых на предприятии. И, на наш взгляд, такая аналитическая работа может дать положительный эффект, многократно превышающий издержки на заработную плату такого сотрудника.

В третью группу мы выделим ТИ, которые очень сложно определить даже косвенным способом. Сюда придется включить расходы предприятия на «откаты», подкуп чиновников, неформальные договоренности, потери времени, связанные с получением разрешений и лицензий и т.п. Информация о таких ТИ недоступна и тщательно скрывается. Статистическая отчетность в принципе не предусматривает выделения такого вида издержек предприятия. Но ни для кого не секрет, что такие нелегальные или полулегальные расходы существуют, даже существуют известные в заинтересованных кругах расценки за осуществление тех или иных действий чиновников. Иногда эти расценки столь велики, что фирма вынуждена в принципе отказываться от того или иного вида предпринимательской деятельности. Но дать им официальную денежную оценку невозможно.

Одной из серьезных проблем при определении и анализе внутрифирменных ТИ является доступность и достоверность информации. 
Как правило, экономическая информация по результатам деятельности фирмы в текущем периоде является коммерческой тайной и не находится в свободном доступе.

Таким образом, мы можем с полным основанием констатировать, что в настоящее время существуют серьезные проблемы в измерении трансакционных издержек отдельной фирмы, связанные с отсутствием теоретико-методологического обоснования необходимости их измерения и с отсутствием унифицированных методик их исчисления. При этом в научной литературе проводятся исследования в данной области и предлагаются различные методы исчисления ТИ. Но каждый автор опирается на свое собственное представление о том, как надо группировать данные издержки, какими формулами пользоваться при расчетах, на что в первую очередь обращать внимание.

Объективная сложность в выработке единой общепризнанной методики измерения трансакционных издержек на микроэкономическом уровне обусловлена во многом спецификой тех сфер и отраслей, в которых функционирует конкретное предприятие. Для одних отраслей объективно важными являются издержки измерения (как, например, на рассматриваемом предприятии); для других (например, в отраслях тяжелой промышленности) особое значение будут иметь издержки совместной координации деятельности; в торговле особое место будет отводиться издержкам на рекламу и т.п. При этом на любом предприятии присутствуют все виды возможных внутрифирменных ТИ, так как последние по своей сущности являются издержками включения фирмы в общеэкономические процессы. Отсюда вытекает не только сложность их подсчета, но и актуальность их измерения с целью дальнейшей оптимизации.

\section{ВЫВОДЫ}

Выше изложенный материал позволяет сделать некоторые обобщенные выводы:

1. Нет единого подхода к классификации трансакционных издержек, что обусловлено многообразием, сложностью и постоянной эволюцией самих трансакций. Любая классификация будет неполной, так как не может учесть все критерии, по которым выделяются те или иные виды ТИ.

2. В самом общем приближении внутрифирменные ТИ можно разделить на предконтрактные и постконтрактные. Среди первых выделяются издержки поиска информации, ведения переговоров, измерения. Для второй группы характерны издержки оппортунистического поведения и издержки спецификации прав собственности. 
3. Сложность и многообразие трансакционных издержек порождает проблему их точной оценки. Отсутствие единой общепризнанной методики их подсчета порождает множество методик, позволяющих прямо или косвенно оценить внутрифирменные ТИ. Каждая методика имеет право на существование, так как в различных отраслях будет наблюдаться специфика организации взаимодействия фирмы с внешней средой.

4. На взгляд авторов, есть смысл разделять внутрифирменные ТИ при их измерении и анализе на три группы в зависимости от точности и возможности их подсчета. В первую группу включаются те ТИ, которые отражается в статистической отчетности предприятия и поддается точному учету. Ко второй группе относятся те ТИ, которые можно определить косвенно через другие показатели, не имеющие однозначной идентификации как трансакционные издержки. Третью группу составят такие виды ТИ, которые не подлежат более-менее точному подсчету в силу их специфики. В первую очередь это касается полулегальных и нелегальных расходов фирмы, связанных с необходимостью преодоления оппортунистического поведения во внешней для фирмы среде.

\section{ЛИТЕРАТУРА}

1. Arrow, K.J. Political and economic evaluation of social effects and externalities / K.J. Arrow / The analysis of public output / Ed. by J. Margolis. N.Y., 1970. - 1-30 p.

2. Норт, Д. Институты, институциональные изменения и функционирование экономики / Д. Норт. - М.: Фонд экономической книги "Начала", 1997. - 200 с.

3. Milgrom, P. Bargaining costs, influence costs, and the organization of economic activity / P. Milgrom, J. Roberts / Perspectives on positive political economy / Ed. by J.E. Alt and K.A. Shepsle. - Cambridge, 1990. - 57-89 p.

4. Уильямсон, О.И. Экономические институты капитализма: Фирмы, рынки, «отношенческая» контрактация / О.И. Уильямсон; научное редактирование и вступительная статья В.С. Катькало; пер. с англ. Ю.Е. Благова [и др.]. - СПб.: Лениздат; CEV Press, 1996. - 702 с.

5. Уильямсон, О.И. Экономические институты капитализма: Фирмы, рынки, «отношенческая» контрактация / О.И. Уильямсон / Научное редактирование и вступительная статья В.С. Катькало; пер. с англ. Ю.Е. Благова [и др.]. - СПб.: Лениздат; CEV Press, 1996. 
6. Рысьмятов, А.3. Теоретические и методологические основы трансакций и трансакционных издержек [Электронный ресурс] / А.3. Рысьмятов, Е.А. Следева, А.А. Набока // Научный журнал КубГАУ. - Краснодар: КубГАУ, 2008. - №02(36). - С. 1-9. - Режим доступа: http://ej.kubagro.ru/2008/02/pdf/04.pdf.(С. 5.) - Дата доступа: 03.04.2016. - C. 5 .

7. Coase, R. The Problem of Social Cost. [Электронный pecypc] / R. Coase // "Journal of Law and Economics". - 1960. - v. 3. - No. 1. - Режим доступа: http://www.libertarium.ru/Coase. - Дата доступа: 10.02.2016.

8. North, D.C. Integrating Institutional Change and Technical Change in Economic History. A Transaction Cost Approach / D.C. North, J.J. Wallis // Journal of Institutional and Theoretical Econoics. - 1994. - V. 150. - № 4. Dec. P. 609-624.

9. Капелюшников, Р.И. Экономическая теория прав собственности / Р.И. Капелюшников. - М.: ИМЭМО, 1990. - 216 с.

10. Ильяшенко, В.А. Структура образования трансакционных издержек / В.А. Ильяшенко // Вестник Саратовского государственного социально-экономического университета. - 2008. - №1 (20). C. 9-11. - C. 10 .

11. Шумакова, О.В. Трансакционные издержки в рыночном хозяйстве АПК: проблемно ориентированный анализ / О.В. Шумакова // Известия Оренбургского государственного аграрного университета. 2010. - № 25-1. С. $127-130 .-$ С. 127.

12. Тисенкова, О.А. Исследование трансакционных издержек мезопроизводственных систем / О.А. Тисенкова // Вестник КГФЭИ. - 2008. №3(12). - С. 24-26. - С. 25.

13. Оганесян, Л.О. Альтернативные принципы классификации трансакционных издержек / Л.О. Оганесян, И.А. Гущина // Известия ВГПУ. - 2011. - №9. -С. 108-109.

14. Оганесян, Л.О. Альтернативные принципы классификации трансакционных издержек / Л.О. Оганесян, И.А. Гущина // Известия ВГПУ. - 2011. - №9. - С. 110.

15. Попова, Л.В. Учет трансакционных издержек в агроформированиях / Л.В. Попова, Е.В. Вобленко // Известия Нижневолжского агроуниверситетского комплекса. - 2011. - №3(23). C. 1-6.

16. Адизес, И. Управление жизненным циклом корпорации / И. Адизес. - Пер. с англ. под науч. ред. А.Г. Сеферяна. - СПб: Питер, 2007. - 384 c. - C. 154. 
17. Подопригора, М.Г. Учет трансакционных издержек на различных этапах жизненного цикла организации / М.Г. Подопригора // Известия ЮФУ. Технические науки. - 2008. - №10. - С. 59-63.

18. Тисенкова, О.А. Исследование трансакционных издержек мезопроизводственных систем / О.А. Тисенкова // Вестник КГФЭИ. - 2008. №3(12). - С. 24-26.

19. Шакиров, Н.Ш. Теория и методология оценки структуры трансакционных издержек / Н.Ш. Шакиров // Актуальные проблемы экономики и права. - 2010. - № 1.- С. 19-31.

20. Вологин, И.С. Трансакционные издержки в деятельности предприятия промышленности / И.С. Вологин, В.В. Соколенко// Вестник ТГЭУ. - 2009. - № 4. - С.42-48.

21. Фишер, Т. Координация управления качеством в свете теории трансакционных издержек /T. Фишер//Проблемы теории и практики управления. - 1999. - № 3. - С. 62-67.

22. Стукач, В.Ф. Исследование трансакционных издержек на рынке агропродовольственных товаров в категориях институциональной экономики / В.Ф. Стукач, О.Н. Крюкова // Современные проблемы науки и образования. - 2010. - №1. - С. 119-125.

23. Тисенкова, О.А. Исследование трансакционных издержек мезопроизводственных систем / О.А. Тисенкова // Вестник КГФЭИ. - 2008. №3(12). - C. 24-26.

Статья поступила в редакциию 06.10.2016 года. 